\title{
Presence of virulence factors in Enterococcus faecalis and Enterococcus faecium susceptible and resistant to vancomycin
}

\author{
Carolina Baldisserotto Comerlato, Mariah Costa Carvalho de Resende, \\ Juliana Caierão/ ${ }^{+}$, Pedro Alves d'Azevedo
}

Universidade Federal de Ciências da Saúde de Porto Alegre, Porto Alegre, RS, Brasil

\begin{abstract}
Despite the increasing importance of Enterococcus as opportunistic pathogens, their virulence factors are still poorly understood. This study determines the frequency of virulence factors in clinical and commensal Enterococcus isolates from inpatients in Porto Alegre, Brazil. Fifty Enterococcus isolates were analysed and the presence of the gelE, asal and esp genes was determined. Gelatinase activity and biofilm formation were also tested. The clonal relationships among the isolates were evaluated using pulsed-field gel electrophoresis. The asal, gelE and esp genes were identified in $38 \%, 60 \%$ and $76 \%$ of all isolates, respectively. The first two genes were more prevalent in Enterococcus faecalis than in Enterococcus faecium, as was biofilm formation, which was associated with gelE and asal genes, but not with the esp gene. The presence of gelE and the activity of gelatinase were not fully concordant. No relationship was observed among any virulence factors and specific subclones of $\mathrm{E}$. faecalis or $\mathrm{E}$. faecium resistant to vancomycin. In conclusion, E. faecalis and $\mathrm{E}$. faecium isolates showed significantly different patterns of virulence determinants. Neither the source of isolation nor the clonal relationship or vancomycin resistance influenced their distribution.
\end{abstract}

Key words: Enterococcus - virulence factors - vancomycin resistance

In recent decades, Enterococcus have emerged as important nosocomial pathogens. Currently, they are recognised as the second-most common cause of urinary tract infections and the third-most common cause of nosocomial bacteraemia (Lindenstrau et al. 2011). Although many species can be recovered from human infections, Enterococcus faecalis is the most frequently recovered, representing more than $90 \%$ of clinical isolates, followed by Enterococcus faecium (Dahlén et al. 2012), which has shown an increase in prevalence in recent years (Fisher \& Phillips 2009). Classically, E. faecalis has been linked to increased virulence, whereas E. faecium commonly exhibits multiresistance characteristics (Sharifi et al. 2012).

Recent studies have associated enterococcal virulence with different factors, such as gelatinase production, Enterococcus surface protein (Esp), aggregation substance (AS) and biofilm formation (Chuang et al. 2009). Gelatinase is a zinc metalloprotease, encoded by gelE, with hydrolytic capacity (Lindenstrau et al. 2011). AS, encoded by a plasmid gene, mediates binding to the host epithelium and it appears to mediate bacterial aggregation during conjugation, facilitating plasmid exchange (Schlievert et al. 2010). The Esp protein, encoded

doi: 10.1590/0074-0276108052013009

Financial support: CNPq, FAPERGS (PRONEM n 11/2058-5)

+ Corresponding author: juli1624@gmail.com

Received 9 November 2012

Accepted 3 May 2013 by the esp gene, seems to contribute to the colonisation and persistence of E. faecalis strains in ascending infections of the urinary tract. In addition, Esp may mediate the interaction with primary surfaces and participate in biofilm formation (Chuang-Smith et al. 2010), which substantially enhances bacterial survival in biopolymers and may also be involved in antimicrobial resistance (Ballering et al. 2009).

Knowledge of the virulence characteristics of circulating Enterococcus strains may help to understand the complex pathogenic process of these opportunistic microorganisms (Sharifi et al. 2012). Data about virulence of Enterococcus circulating strains in Brazil are still scarce (Ruzon et al. 2010). Therefore, the objective of this study was to evaluate the presence of virulence factors in E. faecalis and E. faecium from clinical and surveillance samples.

\section{SUBJECTS, MATERIALS AND METHODS}

Enterococcus were isolated from inpatients in Porto Alegre, southern Brazil, between 2000-2011. The bacteria were recovered from two distinct situations: an $E$. faecalis outbreak that occurred mainly during 2004, with some related strains isolated from 2000 until 2009, and an E. faecium outbreak that occurred during 20102011. To potentially increase the genetic diversity of the strains, non-epidemiologically related Enterococcus strains recovered during the same period were examined. The isolates were from clinically relevant sites and from surveillance cultures (rectal swabs), which were performed by infection control staff during the first outbreak. The samples were maintained in $10 \%(\mathrm{v} / \mathrm{v})$ Skim Milk solution (Molico, Nestlé ${ }^{\circledR}$ ) with 10\% glycerol (v/v) and stored at $-20^{\circ} \mathrm{C}$. 
Isolates were identified by conventional biochemical tests (Teixeira et al. 2011) and susceptibility to vancomycin was determined following the Clinical Laboratory Standards Institute guidelines (CLSI 2011) using broth microdilution to determine the minimal inhibitory concentration (MIC).

Gelatinase activity was characterised as described elsewhere (Marra et al. 2007). Briefly, samples were inoculated into tubes containing $4 \mathrm{~mL}$ of brain heart infusion broth with $4 \%$ gelatin. After incubation at $35-37^{\circ} \mathrm{C}$ for $24 \mathrm{~h}$, the tubes were cooled at $4^{\circ} \mathrm{C}$ for $30 \mathrm{~min}$ and the liquefaction of the medium was observed.

Biofilm formation was determined using the method described proposed by Stepanovic et al. (2000). Briefly, microorganisms were grown in polystyrene microplates and the wells were washed, stained with crystal violet and washed again. The dye was solubilised using an alcohol solution. Then, the absorbance of the solution was measured by determining the optical density (OD) of the wells. The cut-off was defined as the mean OD of eight negative control wells. Based on the OD, the isolates were classified as follows: nonadherent, weakly adherent, moderately adherent and strongly adherent.

The presence of the gelE, esp and asal genes was verified by polymerase chain reaction, as described by Eaton and Gasson (2001). The sequences of primers and annealing temperatures used are shown in Table I. Statistical analysis was performed with SPSS version 19.0, using the chi-square test. The clonal relationships among the isolates were determined by pulsed-field gel electrophoresis (PFGE) and by comparing the fragment patterns after restriction of chromosomal DNA with SmaI, as described elsewhere (Teixeira et al. 1997). Electrophoresis was performed in a CHEF DR III (Bio-Rad) apparatus.

\section{RESULTS}

This study evaluated 50 Enterococcus isolates: 30 E. faecalis and 20 E. faecium. Twenty E. faecalis were vancomycin-resistant enterococci (VRE), with a MIC $\geq$ $256 \mu \mathrm{g} / \mathrm{mL}$, as were all E. faecium. Table II describes the characteristics of the Enterococcus included in the study. Most of the isolates were recovered from urine (30\%).
Other specimens included blood, stool (surveillance cultures), abdominal secretions, catheters, wounds, soft tissue and nephrostomy secretions. Seven isolates had an unidentified source. No relationship was found between the source of isolation and the presence or activity of any virulence factor.

The distribution of virulence factors among the isolates is shown in Table III. Overall, $60 \%$ (30/50) of the enterococci carried gelE. Of these, $66.6 \%(20 / 30)$ presented gelatinase activity. The esp gene was detected in $76 \%(38 / 50)$ of isolates and 38\% (19/50) of all Enterococcus carried the asal gene. Furthermore, 74\% (37/50) of the isolates were biofilm formers. Most E. faecalis were moderate or strong formers, whereas most E. faecium were not able to produce biofilm, or if so, the biofilm was weakly adherent.

Considering vancomycin resistance as a variable, we did not find any significant difference in the presence or activity of virulence factors between resistant and susceptible enterococci. On the other hand, the presence and activity of virulence factors were significantly different between the species. Only VRE isolates were selected to compare virulence characteristics between $E$. faecalis and E. faecium.

E. faecalis carried gelE at a significantly higher frequency and presented gelatinase activity more frequently than E. faecium ( $\mathrm{p}<0.001)$. The presence of the asal gene was also significantly different between the two species ( $\mathrm{p}<0.001)$, being more commonly found in $E$. faecalis than in E. faecium. On the other hand, there was no difference in the frequency of the esp gene between the two species. Significantly more E. faecalis isolates formed biofilms than E. faecium isolates ( $\mathrm{p}=0.003)$.

We also evaluated the association between biofilm formation and the presence of the esp, asal and gelE genes in E. faecalis and E. faecium. Biofilm formation was significantly associated with the presence of the gelE $(\mathrm{p}=0.001)$ and asal genes $(\mathrm{p}=0.03)$, although it was not associated with the esp gene $(\mathrm{p}=0.06)$. Nevertheless, all strongly adherent isolates carried, along with gelE, the esp gene and more than $70 \%$ of the strongly adherent isolates carried all three virulence genes.

PFGE analysis was performed in three groups of isolates: E. faecalis resistant to vancomycin $\left(\mathrm{VRE}_{\mathrm{f}}\right)$ -

TABLE I

Primers and annealing temperatures (AT) used to detect the virulence genes

\begin{tabular}{|c|c|c|c|c|}
\hline Gene & Primers & Sequence ( $\left(5^{\prime}-3^{\prime}\right)$ & $\begin{array}{l}\text { Product } \\
\text { (bp) }\end{array}$ & $\begin{array}{l}\mathrm{AT} \\
\left({ }^{\circ} \mathrm{C}\right)\end{array}$ \\
\hline gelE & $\begin{array}{l}\text { TE9 } \\
\text { TE10 }\end{array}$ & $\begin{array}{l}\text { ACCCCGTATCATTGGTTT } \\
\text { ACGCATTGCTTTTCCATC }\end{array}$ & 419 & 53 \\
\hline esp & $\begin{array}{l}\text { TE34 } \\
\text { TE36 }\end{array}$ & $\begin{array}{l}\text { TTGCTAATGCTAGTCCACGACC } \\
\text { GCGTCAACACTTGCATTGCCGAA }\end{array}$ & 933 & 52 \\
\hline$a g g$ & $\begin{array}{l}\text { TE3 } \\
\text { TE4 }\end{array}$ & $\begin{array}{l}\text { AAGAAAAAGAAGTAGACCAAC } \\
\text { AAACGGCAAGACAAGTAAATA }\end{array}$ & 1,553 & 52 \\
\hline
\end{tabular}

bp: base pairs. 
TABLE II

Characteristics of Enterococcus isolates included in the study

\begin{tabular}{|c|c|c|c|c|}
\hline Species & $\begin{array}{c}\text { Vancomycin MIC } \\
(\mu \mathrm{g} / \mathrm{mL})\end{array}$ & Source & $\begin{array}{l}\text { Clonal } \\
\text { type }\end{array}$ & Year \\
\hline E. faecalis & $>256$ & Stool & $\mathrm{F}_{\mathrm{B}}$ & 2000 \\
\hline E. faecalis & $>256$ & Urine $(\mathrm{n}=2)$ & $\mathrm{F}_{\mathrm{A2}}^{\mathrm{B}}$ & $2001 / 2004$ \\
\hline E. faecalis & $>256$ & Stool & $\mathrm{F}_{\mathrm{A} 2}^{\mathrm{A} 2}$ & 2004 \\
\hline E. faecalis & $>256$ & NI & $\mathrm{F}_{\mathrm{A} 1}^{\mathrm{A} 2}$ & 2004 \\
\hline E. faecalis & $>256$ & Urine & $\mathrm{F}_{\mathrm{Al}}$ & 2004 \\
\hline E. faecalis & $>256$ & Blood $(n=4)$ & $\mathrm{F}_{\mathrm{A} 1}^{\mathrm{Al}}$ & $2004 / 2004 / 2005 / 2008$ \\
\hline E. faecalis & $>256$ & Nefrostomy secretion & $\mathrm{F}_{\mathrm{A} 1}^{\mathrm{Al}}$ & 2004 \\
\hline E. faecalis & $>256$ & Stool $(n=4)$ & $\mathrm{F}_{\mathrm{Al}}^{\mathrm{Al}}$ & 2004 \\
\hline E. faecalis & $>256$ & Catheter & $\mathrm{F}_{\mathrm{A} 1}^{\mathrm{Al}}$ & 2004 \\
\hline E. faecalis & $>256$ & Wound & $\mathrm{F}_{\mathrm{A} 1}$ & 2004 \\
\hline E. faecalis & $>256$ & NI & $\mathrm{F}_{\mathrm{A} 1}^{\mathrm{Al}}$ & 2006 \\
\hline E. faecalis & $>256$ & Sputum & $\mathrm{F}_{\mathrm{A} 1}$ & 2008 \\
\hline E. faecalis & $>256$ & Abdominal secretion & $\mathrm{F}_{\mathrm{A} 1}^{\mathrm{Al}}$ & 2008 \\
\hline E. faecalis & 1 & Soft tissue & $\mathrm{S}_{\mathrm{A}}$ & 2008 \\
\hline E. faecalis & 0.5 & Blood & $\mathrm{S}_{\mathrm{B}}^{\mathrm{A}}$ & 2008 \\
\hline E. faecalis & 0.5 & Soft tissue & $\mathrm{S}_{\mathrm{C}}^{\mathrm{B}}$ & 2009 \\
\hline E. faecalis & 1 & NI & $\mathrm{S}_{\mathrm{D}}$ & 2009 \\
\hline E. faecalis & 2 & Abdominal secretion & $\mathrm{S}_{\mathrm{E}}^{\mathrm{D}}$ & 2009 \\
\hline E. faecalis & 1 & NI & $\mathrm{S}_{\mathrm{F}}$ & 2009 \\
\hline E. faecalis & 0.5 & NI & $\mathrm{S}_{\mathrm{G}}^{\mathrm{r}}$ & 2010 \\
\hline E. faecalis & 0.25 & NI & $\mathrm{S}_{\mathrm{H}}^{\mathrm{G}}$ & 2010 \\
\hline E. faecalis & 2 & NI & $\mathrm{S}_{\mathrm{I}}^{\mathrm{H}}$ & 2010 \\
\hline E. faecalis & 0.5 & Abdominal secretion & $\mathrm{S}_{\mathrm{J}}$ & 2010 \\
\hline E. faecium & $>256$ & Urine & $\mathrm{E}_{\mathrm{B}}$ & 2010 \\
\hline E. faecium & $>256$ & Blood $(n=2)$ & $\mathrm{E}_{\mathrm{A} 2}^{\mathrm{B}}$ & 2011 \\
\hline E. faecium & $>256$ & Blood $(\mathrm{n}=5)$ & $\mathrm{E}_{\mathrm{A} 1}$ & 2011 \\
\hline E. faecium & $>256$ & Urine $(\mathrm{n}=2)$ & $\mathrm{E}_{\mathrm{A} 1}$ & 2011 \\
\hline E. faecium & $>256$ & Urine $(\mathrm{n}=8)$ & $\mathrm{E}_{\mathrm{A} 1}^{\mathrm{A} 1}$ & 2011 \\
\hline E. faecium & $>256$ & Abdominal secretion & $\mathrm{E}_{\mathrm{A} 1}^{\mathrm{Al}}$ & 2011 \\
\hline
\end{tabular}

MIC: minimal inhibitory concentration; NI: not identified.

TABLE III

Distribution of virulence genes, the gelatinase activity and biofilm formation among isolates

\begin{tabular}{|c|c|c|c|c|c|c|c|}
\hline $\begin{array}{l}\text { Group } \\
\text { (n) }\end{array}$ & $\begin{array}{l}\text { Clonal type } \\
\text { (n) }\end{array}$ & $\begin{array}{l}a g g \\
\mathrm{n}(\%)\end{array}$ & $\begin{array}{c}e s p \\
\mathrm{n}(\%)\end{array}$ & $\begin{array}{l}\text { gelE } \\
\mathrm{n}(\%)\end{array}$ & $\begin{array}{c}\text { Gelatinase } \\
\text { n (\%) }\end{array}$ & $\begin{array}{l}\text { Biofilm } \\
\text { n }(\%)\end{array}$ & Virulence genes \\
\hline \multirow{4}{*}{$\begin{array}{l}\mathrm{VRE}_{\mathrm{fm}} \\
(20)\end{array}$} & $\mathrm{E}_{\mathrm{Al}}(15)$ & $1(5)$ & $13(65)$ & - & $1(5)$ & $7(35)$ & agg, esp, gelatinase, biofilm \\
\hline & $\mathrm{E}_{\mathrm{A} 2}(3)$ & - & $2(10)$ & $1(5)$ & - & $1(5)$ & esp, gelE, biofilm \\
\hline & $\mathrm{E}_{\mathrm{B}}(1)$ & - & $1(5)$ & - & - & $1(5)$ & esp, biofilm \\
\hline & Total & $1(5)^{a}$ & $16(80)$ & $1(5)^{a}$ & $1(5)^{a}$ & $9(45)^{a}$ & - \\
\hline \multirow{4}{*}{$\begin{array}{l}\mathrm{VRE}_{f} \\
(20)\end{array}$} & $\mathrm{F}_{\mathrm{Al}}$ & $11(55)$ & $14(70)$ & $18(90)$ & $13(65)$ & $17(85)$ & agg, esp, gelE, gelatinase, biofilm \\
\hline & $\mathrm{F}_{\mathrm{A} 2}$ & $2(10)$ & $1(5)$ & - & - & $1(5)$ & agg, esp, biofilm \\
\hline & $\mathrm{F}_{\mathrm{B}}$ & - & $1(5)$ & $1(5)$ & - & $1(5)$ & esp, gelE, biofilm \\
\hline & Total & $13(65)^{a}$ & $16(80)$ & $19(95)^{a}$ & $13(65)^{a}$ & $19(95)^{a}$ & - \\
\hline $\begin{array}{l}\operatorname{VSE}_{f} \\
(10)\end{array}$ & NRI & $5(50)$ & $6(60)$ & $10(100)$ & $6(60)$ & $9(90)$ & agg, esp, gelE, gelatinase, biofilm \\
\hline Total & Total & $19(38)$ & $38(76)$ & $30(60)$ & $20(40)$ & $37(74)$ & - \\
\hline
\end{tabular}

$a: \mathrm{p}<0.05$; NRI: non-related isolates (unique profiles); VRE $\mathrm{f}_{\mathrm{f}}$ Enterococcus faecalis resistant to vancomycin; $\mathrm{VRE}_{\mathrm{fm}}:$ E. faecium resistant to vancomycin; $\mathrm{VSE}_{\mathrm{f}}$ : . faecalis susceptible to vancomycin. 
representative isolates of the first outbreak period), $E$. faecium resistant to vancomycin $\left(\mathrm{VRE}_{\mathrm{fm}}\right)$ representative isolates of the second outbreak period) and E. faecalis susceptible to vancomycin $\left(\mathrm{VSE}_{\mathrm{f}}\right)$, which was included to possibly increase the genetic variability. Although $\mathrm{VRE}_{\mathrm{f}}$ and $\mathrm{VRE}_{\mathrm{fm}}$ presented a clonal relationship, with a major clone each, the distribution of virulence factors was not homogeneous among the isolates (Table III). The major clones of $\mathrm{VRE}_{\mathrm{f}}$ and $\mathrm{VRE}_{\mathrm{fm}}$ represented 19 of each 20 isolates, with two subclones that were highly related. On the other hand, VSE demonstrated a highly heterogeneous PFGE profile (no clonal relationship among the isolates was observed), with most isolates presenting all evaluated virulence determinants.

\section{DISCUSSION}

Studies focused on enterococcal virulence are complex because the essential factors for pathogenicity have not yet been described. Indeed, virulence in this genus has been typically considered a multifactorial process, with the participation of several genes and their products.

Production of gelatinase is a characteristic mediated by the gelE gene and phenotypically expressed in vitro by liquefaction of a culture medium containing the substrate (Tsikrikonis et al. 2012). We observed Enterococcus isolates that did not produce the enzyme, even though gelE was detected. Indeed, according to Marra et al. (2007), the presence of gelE is not necessarily correlated with gelatinase activity. Some studies suggest that other genes may be associated with gelE expression control. Indeed, Lindenstrau et al. (2011) indicated that mutated genes affect gelE gene expression and possibly regulate gelatinase production. These findings reinforce the complexity of the processes involved in Enterococcus virulence.

There are diverging opinions concerning the role of Esp in biofilm production (Garth et al. 2008). Dworniczek et al. (2012) concluded that there is no clear relationship between the expression of esp or gelE and biofilm formation. Indeed, an analysis by Sillanpää et al. (2010) showed efficient biofilm production in the absence of Esp in $E$. faecium isolates. On the other hand, Chuang-Smith et al. (2010) speculated that Esp may mediate the interaction with primary surfaces and participate in the formation of this phenotype. In addition, Heinkens et al. (2007) showed that Esp is involved in biofilm formation in E. faecium isolates. As our results did not show an association between the presence of esp and biofilm production, we assume that other factors are associated with this phenotype.

We observed a considerable number of E. faecium carrying esp compared with asal and gelE genes, which were detected at very low frequencies among this species. Some clones of vancomycin-resistant E. faecium that are well established in hospitals show high positivity for esp, suggesting that this gene may play an important role in the virulence process (Willems \& Bonten 2007). Besides esp, Willems et al. (2005) detected some other genes and combinations of mutations and recombinations that give nosocomial E. faecium clones adaptive advantages that contribute to their dissemination.
As with esp, gelE gene participation in biofilm formation is also controversial. Some authors have observed that, in fact, the presence of gelatinase enzyme can affect the virulence and the process of biofilm formation in Enterococcus (Dworniczek et al. 2012). However, other authors (Ballering et al. 2009) have demonstrated that gelE is not associated with such phenotypes. Nevertheless, our study demonstrated that gelatinase expression may have influenced biofilm formation.

AS is one of several Enterococcus adhesins that can be targeted for therapy against infectious endocarditis. The expression of asal has an important effect on biofilm formation because this genotype promotes the accumulation of adherent microorganisms to a surface (Schlievert et al. 2010). One study identified several functional subdomains in the Enterococcus asal gene and mutations in these loci drastically reduced the ability to form biofilm (Chuang-Smith et al. 2010). Our study corroborates these findings, since asal was significantly more frequent in biofilm-producing strains.

However, based on our statistical analysis, biofilm formation could not be linked to any specific gene. In fact, this phenotype is multifactorial and depends on a number of genes working together along with extrinsic factors. So far, several other genes or gene sets have been reported as auxiliaries in biofilm formation in Enterococcus, which highlights the complexity and the multifactorial nature of this trait (Dworniczek et al. 2012).

Vancomycin resistance was not associated with more virulent strains in our study. Indeed, according to Giridhara et al. (2010), there is no significant difference in virulence factors, ability to cause infection or vancomycin susceptibility among Enterococcus isolates. Acquired resistance and virulence factors may compromise microorganism fitness. Thus, multiresistance characteristics in strains presenting restricted virulence arsenals are a common feature and are frequently seen in opportunistic pathogens (Foucault et al. 2010, Rigottier-Gois et al. 2011).

Molecular epidemiological studies have reported the spread, around the world, of a hospital-adapted complex of E. faecium designated epidemic clonal complex-17 (CC17), which is associated with the majority of hospital outbreaks and clinical infections on all continents. The global success of $\mathrm{CC} 17$ seems to have been facilitated by the cumulative acquisition of antibiotic resistance, putative virulence traits and the ability to acquire different mobile genetic elements (Deshpande et al. 2007). Although the esp gene seems to be a common characteristic of CC17 strains, its occurrence is not homogeneous (Brilliantova et al. 2010). Brilliantova et al. (2010) evaluated 129 vanA-positive E. faecium isolates, which included two major clones belonging to CC17. Virtually all isolates (91\%) were positive for the gelE gene, in contrast to the 5\% positive rate determined in our study. On the other hand, Brilliantova et al. (2010) did not observe any asal-positive isolates, which is in accordance with our findings.

Our VRE $\mathrm{fm}_{\text {fm }}$ group presented some characteristics of $\mathrm{CC} 17$, such as resistance to ampicillin and non-susceptibility to quinolones (data not shown). Moreover, the 
esp gene was highly prevalent, but not always present. Further studies must be done to determine the sequence type of our isolates.

$\mathrm{VRE}_{\mathrm{f}}$ enterococci have been observed by virtually all authors to have a high prevalence of virulence determinants (Udo \& Al-Sweih 2011, Hasani et al. 2012). Nevertheless, Sharifi et al. (2012 ) studied the distribution of virulence factors and they observed a high frequency of all virulence factors (including gelE and asal) except esp, which reinforces the complexity of the virulence process in this genus.

Although one could expect that virulence traits change depending on the source of isolation, we did not find any such association. Dahlén et al. (2012) compared $E$. faecalis recovered from oral mucosal infections and deep infections and they did not find any discrepancies in the distribution of asal, gelE or esp between both groups. Significant differences in the distribution of virulence factors are potentially achievable by comparing infecting and colonising isolates. However, Johansson and Rasmussen (2012) compared virulence factors (ace, asal, gelE, esp) of E. faecalis from infective endocarditis and normal flora and observed that only biofilm formation had a significantly different occurrence (more pronounced in the normal flora group). Indeed, the source of isolation (including surveillance cultures) did not influence the virulence factor distribution among our enterococcal population.

In terms of molecular epidemiology, it was impossible to associate any virulence factor with any specific subclone of $\mathrm{VRE}_{\mathrm{f}}$ or $\mathrm{VRE}_{\mathrm{fm}}$. On the other hand, among the highly heterogeneous population of $\mathrm{VSE}_{\mathrm{f}}$, the distribution of virulence factors was homogeneous, with most isolates presenting almost all the evaluated virulence determinants. Thus, molecular relatedness does not affect virulence gene distribution (Willems et al. 2005).

Our study has some limitations. The small number of isolates could have compromised the statistical analysis, as could the clonal relationship among them. Moreover, our isolates of $\mathrm{VRE}_{\mathrm{fm}}$ and $\mathrm{VRE}_{\mathrm{f}}$ were closely related and potentially do not represent the real distribution of the putative virulence factors in the enterococcal population. Studies with a higher number of heterogeneous VREs should be performed to clarify each one's role in enterococcal pathogenesis.

In the results presented here, E. faecalis and E. faecium isolates showed significantly different patterns of virulence determinants, which reinforces the findings of other authors (Hasani et al. 2012, Sharifi et al. 2012). In addition, neither the source of isolation nor the clonal relationship or vancomycin resistance influenced the distribution of virulence determinants.

Given the increasing importance of Enterococcus as nosocomial pathogens, the identification of virulence factors associated with invasiveness and disease severity has become an important subject of concern. The development of other mechanisms to control infection, such as preventing Enterococcus biofilm formation or inhibiting the action of other virulence factors, may provide an alternative method of therapy, especially considering that antimicrobial treatment is challenging for this genus.

\section{REFERENCES}

Ballering KS, Kristich CJ, Grindle SM, Oromendia A, Beattie DT 2009. Functional genomics of Enterococcus faecalis: multiple novel genetic determinants for biofilm formation in the core genome. J Bacteriol 191: 2806-2814.

Brilliantova AN, Kljasova GA, Miranova AV, Tishkov VI, Novichkova GA, Bobrynina VO, Sidorenko SV 2010. Spread of vancomycin-resistant Enterococcus faecium in two haematological centres in Russia. Int J Antimicrob Agents 35: 177-181.

Chuang ON, Schlievert PM, Wells CL, Manias DA, Tripp TJ 2009. Multiple functional domains of Enterococcus faecalis aggregation substance Asc10 contribute to endocarditis virulence. Infect Immun 77: 539-548.

Chuang-Smith ON, Wells CL, Henry-Stanley MJ, Dunny GM 2010. Acceleration of Enterococcus faecalis biofilm formation by aggregation substance expression in an ex vivo model of cardiac valve colonization. PLOS ONE 5: e15798.

CLSI - Clinical Laboratory Standards Institute 2011. Performance standard for antimicrobial susceptibility testing, Document M100-S21, CLSI, Wayne, 172 pp.

Dahlén G, Blomqvist S, Almstahl A, Carlén A 2012. Virulence factors and antibiotic susceptibility in enterococci isolated from oral mucosal and deep infections. J Oral Microbiol 4: 10855.

Deshpande LM, Fritsche TR, Moet GJ, Biedenbach DJ, Jones RN 2007. Antimicrobial resistance and molecular epidemiology of vancomycin-resistant enterococci from North America and Europe: a report from the SENTRY Antimicrobial Surveillance Program. Diagn Microbiol Infect Dis 58: 163-170.

Dworniczek E, Piwowarczyk J, Bania J, Kowalska-Krochmal B, Walecka E, Seniuk A, Dolna I, Gosciniak G 2012. Enterococcus in wound infections: virulence and antimicrobial resistance. Acta Microbiol Immunol Hung 59: 263-269.

Eaton TJ, Gasson MJ 2001. Molecular screening of Enterococcus virulence determinants and potential for genetic exchange between food and medical isolates. Appl Environ Microbiol 67: 1628-1635.

Fisher K, Phillips C 2009. The ecology, epidemiology and virulence of Enterococcus. Microbiol 155: 1749-1757.

Foucault ML, Depardieu F, Courvalin P, Grillot-Courvalin C 2010. Inducible expression eliminates the fitness cost of vancomycin resistance in enterococci. Proc Natl Acad Sci 107: 16964-16969.

Garth AJ, Swogger E, Wolcott R, deLancey Pulcini E, Secor P, Sestrich J, Costerton JW, Stewart OS 2008. Biofilms in chronic wounds. Wound Repair Regen 16: 37-44.

Giridhara Upadhyaya PM, Umapathy BL, Ravikumar KL 2010. Comparative study for the presence of enterococcal virulence factors gelatinase, hemolysin and biofilm among clinical and commensal isolates of Enterococcus faecalis. $J$ Lab Physicians 2: 100-104.

Hasani A, Sharifi Y, Ghotaslou R, Naghili B, Hasani A, Aghazadeh M, Milani M, Mazmani A 2012. Molecular screening of virulence genes in high-level gentamicin-resistant Enterococcus faecalis and Enterococcus faecium isolated from clinical specimens in Northwest Iran. Indian J Med Microbiol 30: 175-181.

Heikens E, Bonten MJ, Willems RJ 2007. Enterococcal surface protein Esp is important for biofilm formation of Enterococcus faecium E1162. J Bacteriol 189: 8233-8240.

Johansson D, Rasmussen M 2012. Virulence factors in isolates of Enterococcus faecalis from infective endocarditis and from the normal flora. Microb Pathog 55: 28-31.

Lindenstrau AG, Pavlovic M, Bringmann A, Behr J, Ehrmann MA, Vogel RF 2011. Comparison of genotypic and phenotypic cluster 
analyses of virulence determinants and possible role of CRISPR elements towards their incidence in Enterococcus faecalis and Enterococcus faecium. Syst Appl Microbiol 34: 553-560.

Marra A, Dib-Hajj F, Lamb L, Kaczmarek F, Shang W, Beckius G, Millici AJ, Medina I, Gootz TD 2007. Enterococcal virulence determinants may be involved in resistance to clinical therapy. Diagn Microbiol Infect Dis 58: 59-65.

Rigottier-Gois L, Alberti A, Houel A, Taly JF, Palcy P 2011. Largescale screening of a targeted Enterococcus faecalis mutant library identifies envelope fitness factors. PLoS ONE 6: e29023.

Ruzon FI, Paula SB, Kanoshiki RL, Santos JP, Kerbauy G, Kobayashi RKT, Yamauchi LM, Perugini MRE, Yamada-Ogatta SF 2010. Virulence determinants in vancomycin-resistant Enterococcus faecium vanA isolated from different sources at University Hospital of Londrina, Paraná, Brazil. J Microbiol 48: 814-821.

Schlievert PM, Chuang-Smith ON, Peterson ML, Cook LC, Dunny GM 2010. Enterococcus faecalis endocarditis severity in rabbits is reduced by $\operatorname{IgG}$ Fabs interfering with aggregation substance. PLoS One 5: e13194.

Sharifi Y, Hasani A, Ghotaslou R, Varshochi M, Hasani A, Aghazadeh M, Milani M 2012. Survey of virulence determinants among vancomycin resistant Enterococcus faecalis and Enterococcus faecium isolated from clinical specimens of hospitalized patients of northwest of Iran. Open Microbiol J 6: 34-39.

Sillanpää J, Nallapareddy SR, Singh KV, Prakash VP, Fothergill T, Ton-That H, Murray BE 2010. Characterization of the ebpfm pilus-encoding operon of Enterococcus faecium and its role in biofilm formation and virulence in a murine model of urinary tract infection. Virulence 1: 236-246.

Stepanovic S, Vucovic D, Savic B, Svabic-Vlahovic M 2000. A modified microtiter-plate test for quantification of staphylococcal biofilm formation. J Microbiol Methods 40: 175-179.

Teixeira LM, Carvalho MGS, Merquior VLC, Steigerwalt AG, Brenner DJ, Facklam RR 1997. Phenotypic and genotypic characterization of Vagococcus fluvialis, including strains isolated from human sources. J Clin Microbiol 35: 2778-2781.

Teixeira LM, Carvalho MGS, Shewmaker PL, Facklam RR 2011. Manual of clinical microbiology, 10th ed., American Society for Microbiology, Washington DC, $2630 \mathrm{pp}$.

Tsikrikonis G, Maniatis AN, Labrou M, Ntokou E, Michail G, Daponte A, Stathopoulos C, Tsakris A, Pournaras S 2012. Differences in biofilm formation and virulence factors between clinical and fecal enterococcal isolates of human and animal origin. Microb Pathog 52: 336-343.

Udo EE, Al-Sweih N 2011. Frequency of virulence-associated genes in Enterococccus faecalis isolated in Kuwait hospitals. Med Princ Pract 20: 259-264.

Willems RJ, Top J, Saten MV, Robinson DA, Coque TM, Baquero F, Grundmann H, Bonten MJ 2005. Global spread of vancomycinresistant Enterococcus faecium from distinct nosocomial genetic complex. Emerg Infect Dis 11: 821-828.

Willems RJL, Bonten MJM 2007. Glycopeptide-resistant enterococci: deciphering virulence, resistance and epidemicity. Curr Opin Infect Dis 20: 384-390. 